\title{
Traumatic neonatal intracranial bleeding and stroke
}

\author{
Paul Govaert, Piet Vanhaesebrouck, Claudine de Praeter
}

\begin{abstract}
Ischaemia within the regions supplied by vertebral and posterior cerebral arteries has been described as a complication of birth injury, either by direct trauma or by compression from a herniated temporal uncus. Ischaemia within the territory of the middle cerebral artery has been documented after a stretch injury of the vessel's elastica interna. From a series of seven personal observations on birth trauma and related cerebral stroke, we describe three neonates with the uncal herniation type of occipital stroke and four infants with hypoperfusion of the middle cerebral artery or one of its major branches. In three of the latter a basal convexity subdural haemorrhage probably induced the ischaemia, whereas in the other it was associated with haemorrhagic contusion of the parietal lobe. Experimental work and reports on older children support the idea that vasospasm due to surrounding extravasated blood can be one of the responsible mechanisms. Both forceps delivery and difficult vacuum extraction can be implicated in this supratentorial injury, leading to permanent neurological damage in at least half of the survivors in this series.
\end{abstract}

Arterial cerebral infarction has become a frequent diagnosis in the newborn. At postmortem examination its incidence can be $17 \%$ in term neonates. ${ }^{1}$ Diverse aetiopathogenic mechanisms generate this lesion. ${ }^{1-8}$ Several authors have drawn attention to elusive neonatal arterial cerebral occlusion. ${ }^{9-11}$ Emphasis has been put on a characteristic presentation with seizures, either focal or general. 245912

Mechanical birth trauma has been recognised as a direct cause of intracranial arterial injury in four different patterns: laceration of the middle meningeal artery after difficult instrumental delivery ${ }^{13}$; stretch injury of the vertebral artery and its branches ${ }^{14}$; occlusion of the posterior cerebral artery after uncal herniation due to intracranial hypertension ${ }^{15} 16$; and finally, stretch injury of the middle cerebral artery in the absence of supratentorial subdural bleeding. ${ }^{17}$ From a review of 10 patients described in the literature and seven personal observations showing an association of traumatic intracranial bleeding and arterial cerebral ischaemia, we propose yet another pathogenesis: supratentorial basal convexity subdural haematoma and subsequent occlusion of the middle cerebral artery. Haemorrhagic contusion of the parietal lobe due to depression of fractured bone fragments could also be contributive.

\section{Case reports}

CASE 1

This girl, the second of female twins, was delivered at 38 weeks of gestation with three emergency vacuum tractions because of fetal bradycardia. Her Apgar scores were 4 and 6 at 1 and 5 minutes. She weighed $2270 \mathrm{~g}$ at birth and was referred promptly because of subgaleal haemorrhage with hypovolaemic shock. Neither seizures nor intracranial hypertension were part of her clinical evolution. A computed tomogram confirmed the epicranial bleeding and revealed small ventricle cavities, dehiscence between the left parietal and occipital bone, as well as a distinct extracerebral haemorrhage overlying the left tentorial leaflet adjacent to the posterior falx and left occipital cerebral lobe (fig 1A). A repeat computed tomogram on day 8 , taken because of focal electroencephalographic (EEG) disturbances demonstrated residual subdural blood and additional marked hypodensity of the left parietotemporal area (fig 1B). A Doppler ultrasound scan showed symmetrical flow velocities in both middle cerebral arteries. At the age of 6 months the ultrasound image of the brain was symmetrically normal but detailed neurological examination suggested a mild right spastic hemiplegia.

CASE 2

After an uneventful pregnancy this firstborn boy was delivered at term with a difficult vaginal delivery complicated by persistent occipitoposterior position, a long second stage (135 minutes) and failed forceps traction. Nevertheless his Apgar score was 9 at 1 and 5 minutes. He weighed $3450 \mathrm{~g}$. Obvious neonatal problems were not recorded. Pathological density of the right temporal region on the ultrasound scan prompted computed tomography on the sixth day. The right tentorial leaflet appeared covered with blood, extending into the cerebral parenchyma of the temporal and occipital lobes. In front of the bleeding an area of hypodensity was seen to the level of Reil's insula (fig 2). At 6 months both the ultrasound scan and neuromotor development remained within normal limits. 

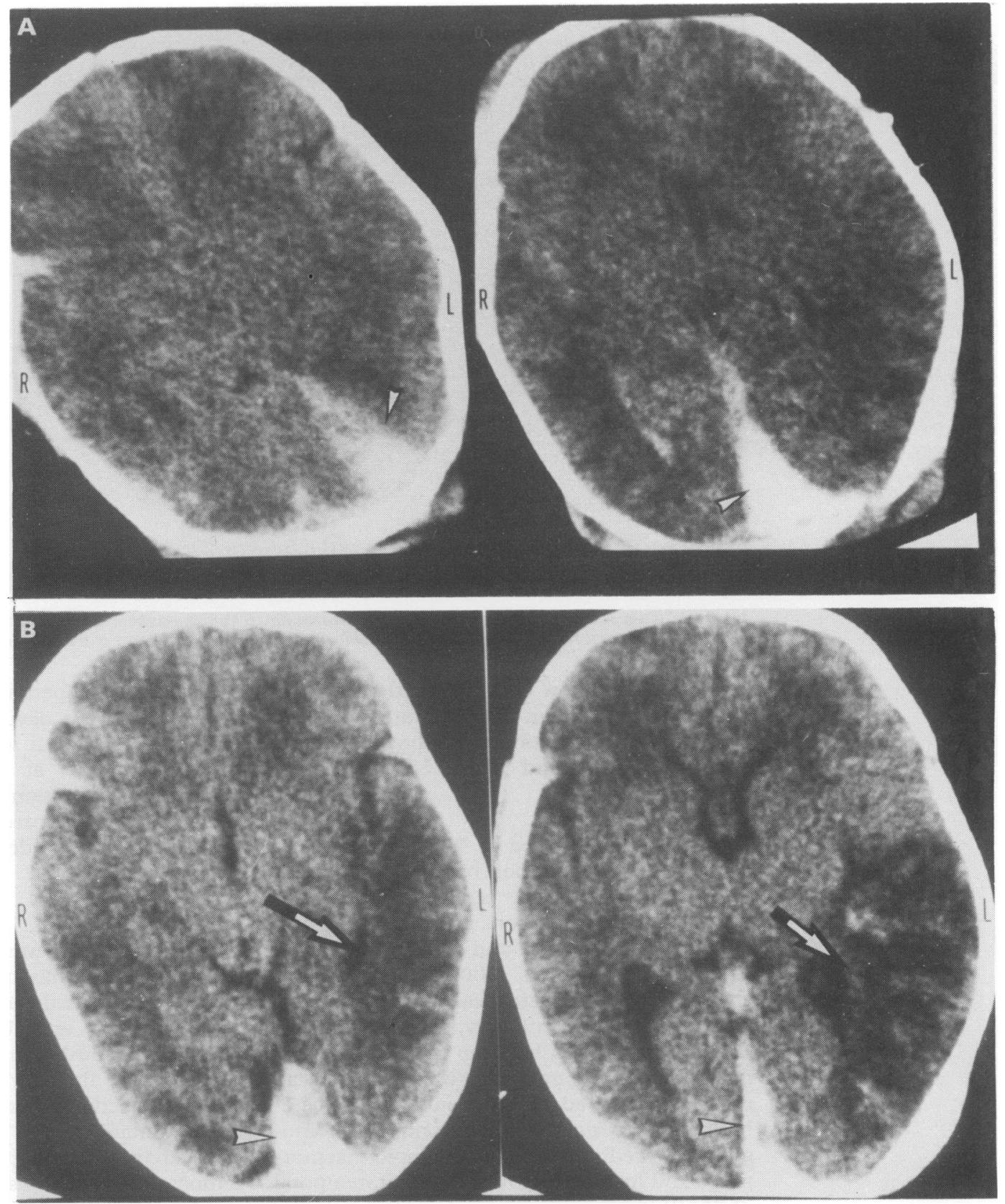

Figure 1 Case 1, uncontrasted computed tomograms. (A) On day 2, a supratentorial haemorrhage is visible mainly above the lefi tentorial leaflet and within the posterior interhemispheric fissure (arrowheads). (B) On day 8, there are residual haemorrhagic densities (arrowheads) and there is a hypodense territory around the lefi middle cerebral artery (arrows).

CASE 3

This girl was delivered by breech at term. The second stage took 26 minutes. Apgar scores were 9 and 10 at 1 and 5 minutes. She weighed $3010 \mathrm{~g}$ at birth. Six hours later her fontanelle became tense and she developed general seizures, hypotonia, and lethargy. Her cry was high pitched. Endotracheal ventilatory support was given for recurrent apnoea with gasping and a fixed bradycardia. Opisthotonus, Battle's sign (retroauricular cephalhaematoma), and a left facial palsy were recorded upon admission. Lumbar cerebrospinal fluid was bloodstained. An emergency computed tomogram demonstrated bilateral peritentorial bleeding and left basal convexity subdural haemorrhage. The girl died on day 3 with intractable seizures. Necropsy revealed infarction in the parietal region of the left middle cerebral artery.
CASE 4

This firstborn boy was delivered by breech at 37 weeks of gestation. After a short first stage of labour, the breech passed easily but considerable difficulty was met with while freeing the arms and delivering the head. His Apgar scores were 1 and 2 at 1 and 5 minutes. He weighed $1340 \mathrm{~g}$ at birth. Several hours later he was referred with cyanosis, apnoea, clonic seizures, and hyponatraemia. Intracranial hypertension remained present for several days. The computed tomogram on day 5 showed bilateral basal convexity subdural haemorrhage, most pronounced on the right; both temporal lobes. seemed hypodense especially medially (fig 3). After recovering from the acute episode he needed plication of the right diaphragm for permanent phrenic nerve palsy and orthopaedic treatment of a fractured right humerus as well as a dislocated left 


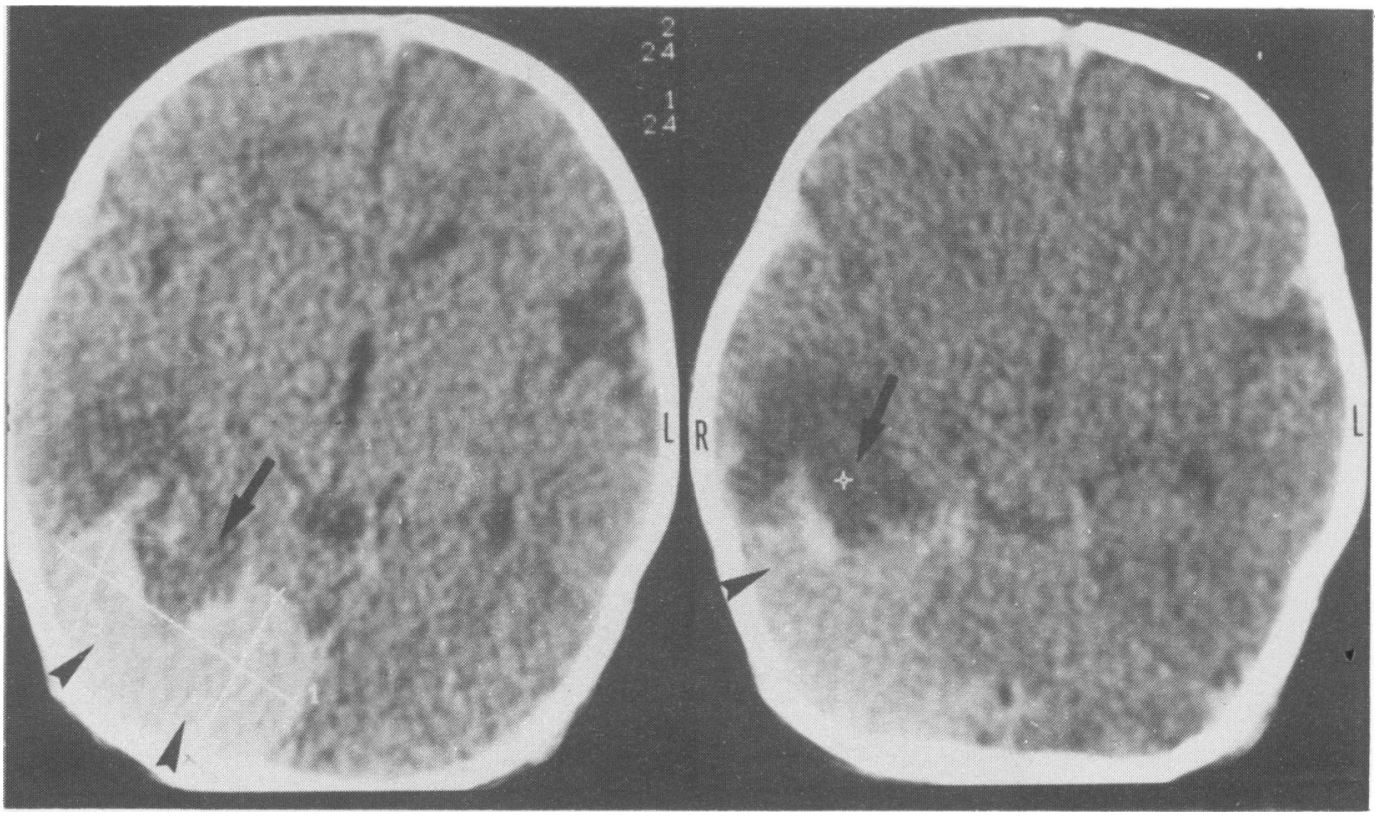

Figure 2 Case 2, uncontrasted computed tomograms on day 6 showing combined subdural and intracerebral haemorrhage in the right temporal region (arrowheads) and white matter hypodensity of part of the temporal lobe (arrows).

shoulder. On follow up at 2 months a control computed tomogram demonstrated bilateral occipital lobe infarction. This boy developed spastic tetraplegia and cortical blindness.

CASE 5

This girl was delivered at 42 weeks of gestation by caesarean section because of occipitoposterior presentation, cephalopelvic disproportion, and decelerations in the second stage. Her Apgar score was 8 and 10 at 1 and $5 \mathrm{~min}$ utes. Birth weight was $3500 \mathrm{~g}$. Six hours later she presented with left focal seizures, convulsive apnoea, a shrill cry, and hypotonia. Palpable separation between the right and left frontal bones was noticed. An ultrasound scan revealed increased densities in the right cerebral parenchyma while the computed tomogram showed diffuse subarachnoid haemorrhage and hypodensity of the occipitotemporal cerebral parenchyma. Focal disturbance of the EEG was present over the right hemisphere.

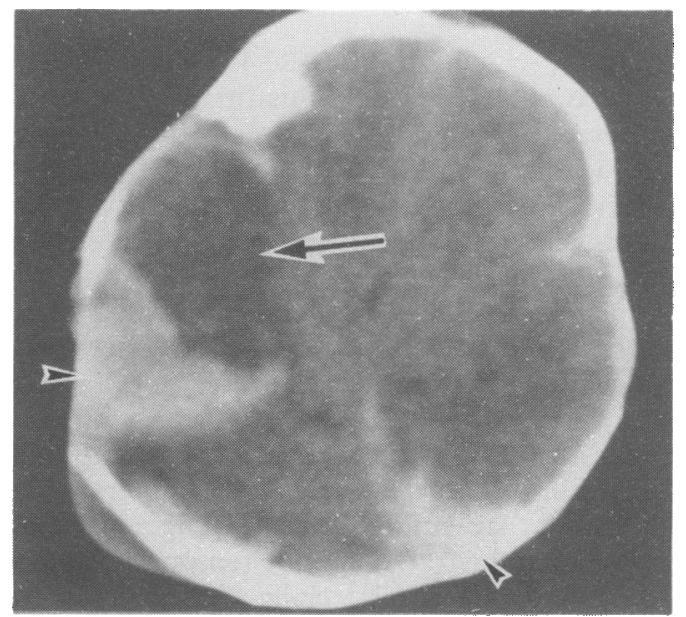

Figure 3 Case 4, uncontrasted computed tomogram on day 5 showing bilateral basal convexity subdural haemorrhage, mainly on the right (arrowheads) with associated temporal lobe hypodensity (arrow).
Subtle seizures persisted for two weeks, as well as skew eye deviations and a left hemiparalysis. Her fundi were normal. The computed tomogram at 3 months showed the sequelae of infarction within the territory of the right posterior cerebral artery (fig 4). At 2 years neuromotor development was within normal limits.

CASE 6

This firstborn boy was delivered by breech at 39 weeks of gestation. Fundal pressure was exerted to deliver the aftercoming head. Apgar scores were 1 and 4 at 1 and 5 minutes respectively. Birth weight was $2350 \mathrm{~g}$. In the course of the first day he became pale, hypotonic, and lethargic and was referred with a tense fontanelle and because of suspected extracerebral bleeding shown on a computed tomogram. Neither seizures nor anisocoria were observed. Heart rate was steady at around 120 beats/minute. A lentiform density on ultrasound and computed tomography was pathognomonic of epidural haematoma (fig 5). There appeared to be a linear fracture of the right parietal bone. Hypodensity of the ipsilateral occipitotemporal cerebral brain tissue and increase of intracranial pressure prompted neurosurgical intervention on day 3. Under local anaesthesia the haematoma, partially liquefied, was aspirated through a dural incision via the lambdoid suture. In the immediate postoperative period, the fontanelle lost its tension and both the midline shift and the parenchymal hypoperfusion disappeared. A residual epidural hygroma resorbed over the ensuing days. Within the first months of life clinical suspicion of Prader-Willi syndrome was confirmed by a typical deletion of chromosome 15.

\section{CASE 7}

This girl, only known to us by her computed tomograms and a limited clinical history, was 


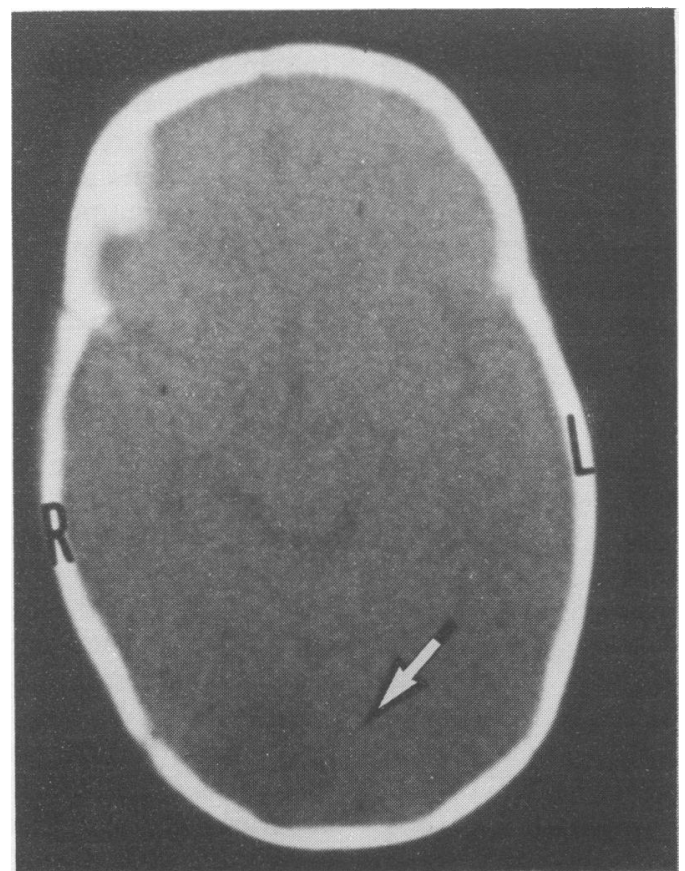

Figure 4 Case 5, uncontrasted computed tomogram at 3 months showing focal tissue loss within the territory of the right posterior cerebral artery.

born at term with unspecified difficult vacuum extraction. She presented with subaponeurotic bleeding and soft neurological signs. Within the neonatal period conventional radiographs and computed tomograms showed bilateral parietal bone fractures (with depression of the anterior fracture margins on the right), subarachnoid and falcial bleeding, a small convexity subdural haematoma on the right, and multifocal hyperdensity of the right postinsular (sub)cortex suggesting cerebral contusion (fig 6A). At the age of 14 months a left spastic hemiplegia was observed. She had a triangular brain defect within the posterior

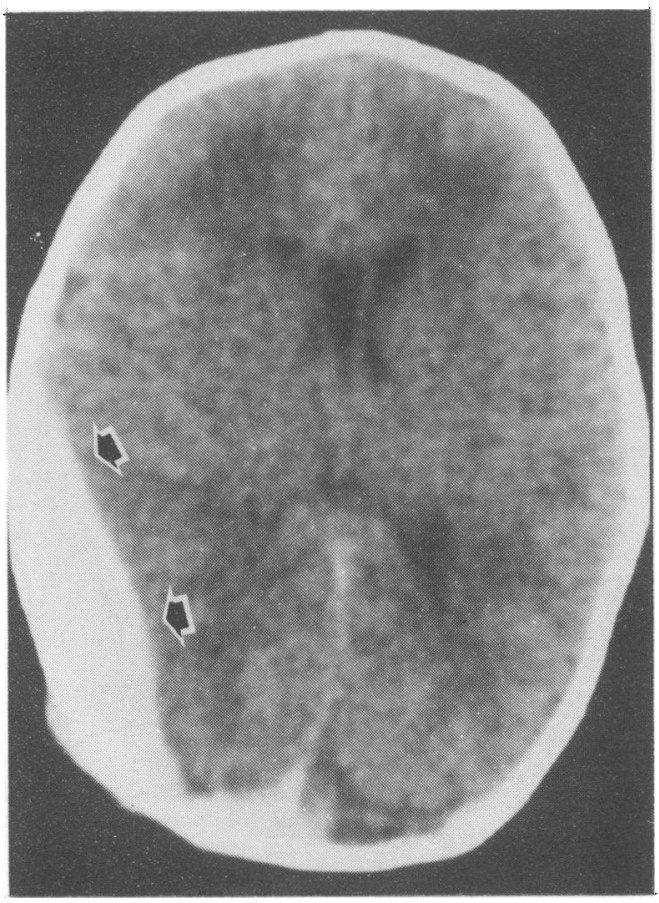

Figure 5 Case 6, uncontrasted computed tomogram on day 2 showing large lentiform density along the right dural membrane. territory of the right middle cerebral artery (fig 6B).

\section{Discussion}

Ischaemia within the regions supplied by the middle or posterior cerebral artery after mechanical trauma at birth has been reported in about 10 living patients. This association was convincingly introduced by Remillard et $a l$ in studying eight patients, aged 3 to 39 years, with temporal lobe epilepsy, homonymous hemianopsia or quadrantanopsia, and enlargement of the occipitotemporal lateral ventricle area. ${ }^{16}$ The difficult births in five of these patients, one with forceps extraction, and the related angiographic demonstration of occlusion of the posterior cerebral artery or its calcarine and occipitoparietal branches, were very suggestive of a perinatal insult.

The link between mechanically difficult delivery and temporal lobe epilepsy was established several years later in a report on two boys delivered at full term with difficult vacuum extraction, presenting with psychomotor seizures at 4 and 10 years respectively. ${ }^{15}$ The first one presented with acute neonatal supratentorial convexity subdural bleeding, whereas the second had a growing 'cephalhaematoma'. The computed tomogram at follow up documented a right occipital porencephalic lesion in both. The authors re-emphasised that in older children and adults temporal lobe herniation through the tentorial aperture had been shown to occlude the posterior cerebral artery and induce incisural sclerosis. ${ }^{18} 19$

A different and well documented neonatal stretch injury of the middle cerebral artery was reported in a full term girl delivered by caesarean section after a failed high forceps extraction attempt. ${ }^{17}$ Lumbar cerebrospinal fluid in this child was bloodstained, while a computed tomogram suggested falcial bleeding and brain oedema. She died on day 4. Postmortem examination revealed several foci of subarachnoid haemorrhage, a soft and swollen right cerebrum in the distribution zone of the middle cerebral artery with central haemorrhagic necrosis, right uncal herniation and bilateral cerebellar coning. The middle cerebral artery carried a thrombus $0.8 \mathrm{~cm}$ from its origin. Light and electron microscopy showed disruption of the lamina elastica interna near the vessel occlusion. It was the author's conviction that this lesion followed stretching of the vessel during difficult delivery.

The growing interest in perinatal arterial cerebral stroke encouraged description, during the eighties, of at least six additional instances where birth trauma may have generated this event. They presented with unilateral middle cerebral artery occlusion after forceps delivery, ${ }^{512} 2021$ except for one with precipitate vaginal birth. ${ }^{22}$ Several authors mentioned intact neurological survival. ${ }^{512}$ Supratentorial subdural bleeding (on magnetic resonance imaging) was referred to only in one report. ${ }^{23}$

In his monograph on cranial birth trauma up to 1964 , Schwartz showed limited interest 

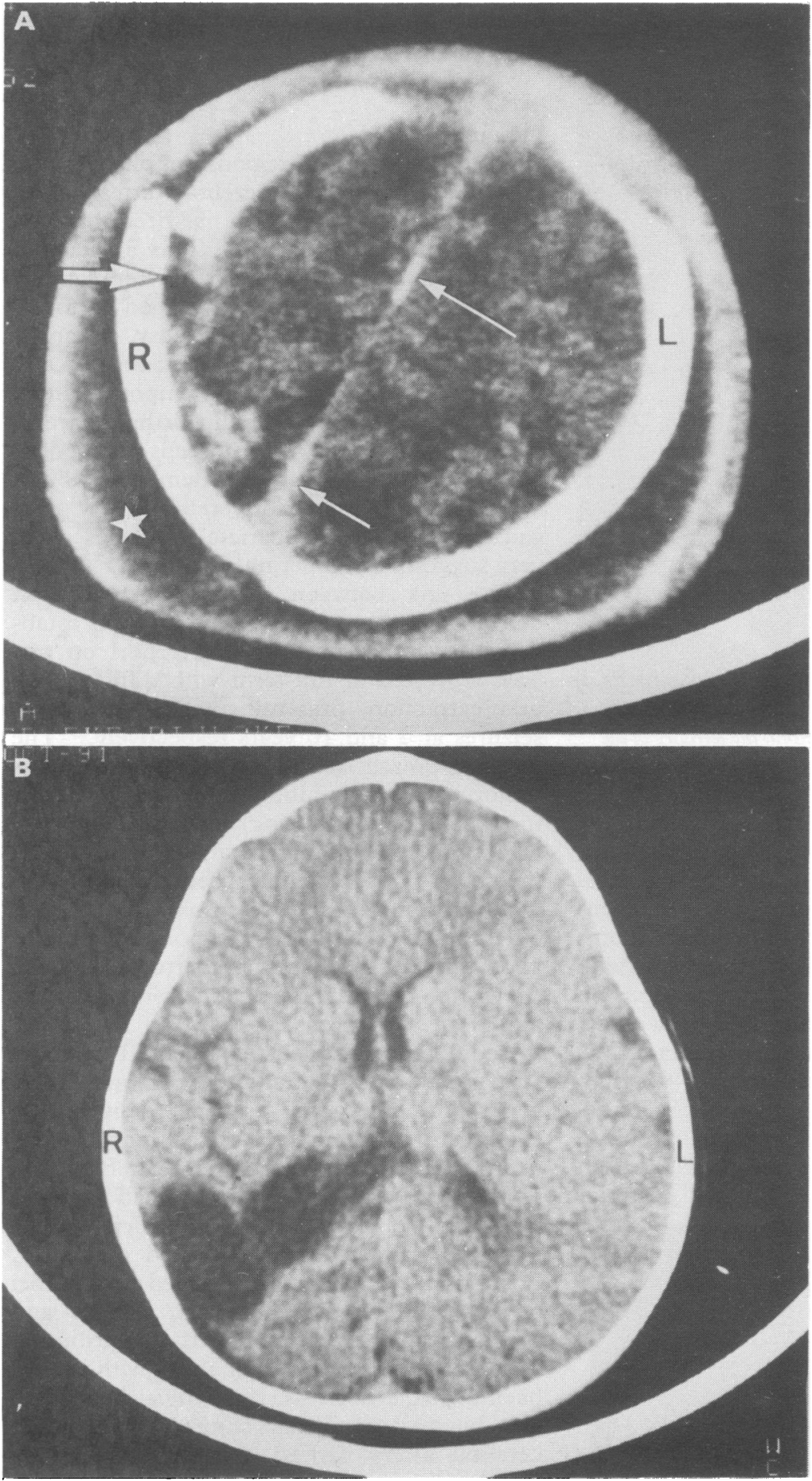

Figure 6 Case 7, uncontrasted computed tomograms. (A) On day 2, showing extensive subgaleal bleeding (star), subarachnoid and intradural haemorrhage (small arrows) and convexity subdural haemorrhage (large arrow) underneath a depressed fracture margin.

(B) At 14 months, showing a triangular defect in the posterior region of the right middle cerebral artery. length, occluded part or whole of the vessel lumen. Some of them arose from torn arterial branches near their origin. Obstruction of one vertebral artery was sufficient to produce bilateral lesions in the brain stem, cerebellum, and occipitotemporal cerebral cortex.

We believe that in the present report cases 4,5 , and 6 fit the mechanism of supratentorial intracranial hypertension leading to uncal herniation and thus causing occlusion of the ipsilateral posterior cerebral artery. ${ }^{15} 16$ The first three cases suggest the existence of another mechanism: basal convexity subdural bleeding leading to occlusion of the ipsilateral middle cerebral artery or its branches. This vessel obstruction might follow stretch injury and subsequent thrombosis, ${ }^{17}$ direct compression by the space occupying haematoma, or arterial embolism. Vasospasm due to the presence of surrounding subarachnoid haemorrhage, as in adults, may well be another mode of genesis. ${ }^{25}$ In favour of this hypothesis is the observation in our first child of the absence of ischaemia on day 2 and its subsequent appearance on day 8 . The necessity of performing a scan in the second week of life to detect arterial cerebral stroke in neonates with seizures, is already recognised. ${ }^{5}$ Attenuation of affected zones on an uncontrasted computed tomogram normally presents within hours after occlusion, rendering unlikely the hypothesis of direct arterial damage in our first patient. ${ }^{26}$ Experimental work supports the idea of erythrocyte induced perihaemorrhagic vasoconstriction of isolated cat middle cerebral arteries. ${ }^{27}$ In addition, spasm of the middle cerebral artery has been reported in older children with head and neck injury. ${ }^{28}$

The absence of left predilection, currently observed in neonatal stroke in general, in this series of trauma related cerebral infarctions is

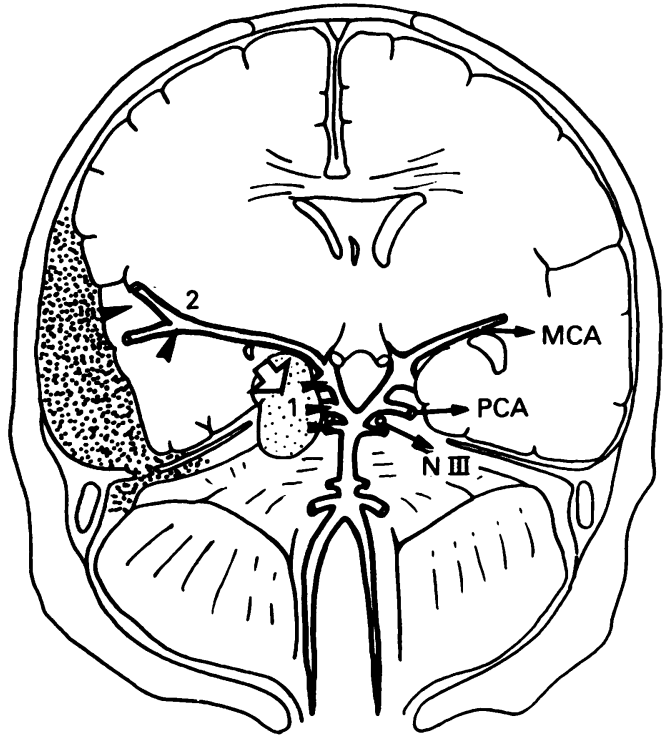

Figure 7 Schematic drawing of two mechanisms generating post-traumatic arterial cerebral occlusion. (1) Uncal herniation (large open arrow) leading to compression (arrowheads) of the posterior cerebral artery (PCA), middle cerebral artery (MCA) and/or oculomotor nerve $(N$ III). (2) Basal convexity subdural haemorrhage leading to compressions and/or spasm of the middle cerebral artery or its branches (arrows). neonates with haemorrhage in the adventil coat of one or both vertebral arteries. These 
compatible with a local and not an embolic phenomenon. ${ }^{29}$ Whatever the underlying mechanism, both the posterior and middle cerebral artery are vulnerable to occlusion after peritentorial subdural bleeding (fig 7). Whereas an isolated subdural haematoma often leaves no neurological sequelae, its association with arterial hypoperfusion predisposes to cerebral palsy if the affected region becomes ischaemic as happened to four of the six survivors in our series.

In case 7 arterial occlusion of a posterior branch of the middle cerebral artery might have been brought about by compression from swollen brain parenchyma, in addition to the above mentioned mechanisms. Of some importance may be the rarity of these lesions after breech delivery (only three in 17 reviewed cases) and the possibility of their occurrence after vacuum as well as forceps extraction, supporting the proposed hypothesis of supratentorial injury as an initiator.

In conclusion, we suggest that compression and/or spasm of the middle cerebral artery or its branches, as a consequence of basal convexity subdural haemorrhage or parietal cerebral contusion, is one cause of traumatic neonatal arterial cerebral stroke.

We are indebted to Dr $S$ van Werveke, Dr V de Telder, Dr $\mathrm{L}$ Callewaert, and Dr P Jeannin for entrusting to us the care of their special birth trauma cases and to Eric and Will for their photographic skills.

1 Barmada MA, Moosy J, Shuman RM. Cerebral infarcts with arterial occlusion in neonates. Ann Neurol 1979;6:495-502.

2 Clancy R, Malin S, Larague D, Baumgart S, Younkin D. Focal motor seizures heralding stroke in full-term neonates. Am f Dis Child 1985;139:601-6.

3 Klesh KW, Murphy TF, Scher MS, Buchanan DE, Maxwell EP, Guthrie RD. Cerebral infarction in persistent pulmonary hypertension of the newborn. Am $f$ Dis Child 1987;141:852-7.

4 Levy SR, Abroms IF, Marshall PC, Rosquete EE. Seizures and cerebral infarction in the full-term newborn. Ann Neurol 1985;17:366-70.

5 Mannino FL, Trauner DA. Stroke in neonates. $f$ Pediatr 1983;102:605-10.
6 Ment LR, Duncan CC, Ehrenkranz RA. Perinatal cerebral infarction. Ann Neurol 1984;16:559-68.

7 Ment LR, Duncan CC, Ehrenkranz RA. Perinatal cerebral infarction. Semin Perinatol 1987;11:142-54.

8 Volpe JJ. Neurology of the newborm. 2nd Ed. Philadelphia: WB Saunders, 1987:229-32.

9 Mantovani JF, Gerber GJ. 'Idiopathic' neonatal cerebral infarction. Am $\mathcal{F}$ Dis Child 1984;138:359.

10 Raine J, Davies H, Gamsu HR. Multiple idiopathic emboli in a full term neonate. Acta Paediatr Scand 1989;78:644-6.

1 Roodhooft AM, Parizel PM, Van Acker KJ, Deprettere AJR, Van Reempts PJ. Idiopathic cerebral infarction with paucity of symptoms in the full-term neonate. Pediatrics paucity of sympto $1987 ; 80: 381-5$.

12 Billard C, Banker BQ. Neonatal meningitis. A clinical and pathological study of 29 cases. Pediatrics 1966;38:6-24.

13 Schwartz P. Geburtsschaden bei Neugeborenen. Jena: Gustav Fischer Verlag, 1964:150-1.

14 Yates PO. Birth trauma to the vertebral arteries. Arch Dis Child 1959;34:436-41.

15 Deonna T, Prod'hom L-S. Temporal lobe epilepsy and hemianopsia in childhood of perinatal origin. Neuropadiatrie 1980;11:85-90.

16 Remillard GM, Ethier R, Andermann F. Temporal lobe epilepsy and perinatal occlusion of the posterior cerebral artery. Neurology 1974;24:1001-9.

17 Roessmann U, Miller RT. Thrombosis of the middle cerebral artery associated with birth trauma. Neurology 1980;30:889-92.

18 Earle KM, Baldwin M, Penfield W. Incisural sclerosis and temporal lobe seizures produced by hippocampal herniation at birth. Archives of Neurological Psychiatry tion as at birth.

19 Lindenberg $\mathbf{R}$. Compression of brain arteries as pathogenetic factor for tissue necroses and their areas of genetic factor for tissue necroses and their areas

20 Fenichel GM, Webster DL, Wong WKT. Intracranial hemorrhage in the term newborn. Arch Neurol 1984;41:30-4.

21 Hill A, Martin DJ, Daneman A, Fitz CR. Focal ischemic cerebral injury in the newborn: diagnosis by ultrasound and correlation with computed tomographic scan. Pediatrics 1983;71:790-3.

22 Halsey AB, Stoddard RA. Neonatal cerebral infarction. 7 Pediatr 1984;104:957-8.

23 Hanigan WC, Morgan AM, Stahlberg LK, Hiller JL. Tentorial hemorrhage associated with vacuum extraction. Pediatrics 1990;85:534-9.

24 Krauland W. Riß der Art. Basilaris als Geburtzverletzung. Beitr Gerichtl Med 1952;19:82.

25 Reulen H-J, Philippon J. Prevention and treatment of delayed ischaemic dysfunction in patients with subarachnoid haemorrhage. An update. Acta Neurochir (Wien) 1988; Suppl 45.

26 Raybaud CA, Livet M-O, Jiddane M, Pinsard N. Radiology of ischemic strokes in children. Neuroradiology 1985;27:567-78.

27 Edvinsson L, Lou HC, Tvede $K$. On the pathogenesis of regional cerebral ischaemic in intracranial haemorrhage: a causal influence of potassium? Pediatr Res 1986;20: 478-80.

28 Frantzen E, Jacobsen HH, Therkelsen J. Cerebral artery occlusions in children due to trauma to the head and neck. Neurology 1962;11:695-700.

29 Mannino FL, Trauner DA. Neonatal cerebral infarction. f Pediatr 1984;104:957-8. 